\title{
A EVOLUĢÃO DAS REDES ELETRÓNICAS DE COMUNICAÇÃO E O USO ESTRATÉGICO DE INTRANET POR UNIDADES DE INFORMAÇÃO
}

\section{Adriana Maria Evaristo Martinez}

\begin{abstract}
Resumo
Apresenta a evolução das redes eletrônicas de comunicação, culminando com a propagação da Internet na década de 90 e, em seguida, o emprego das Intranets em redes corporativas e educacionais. Define o tema Intranet, seu funcionamento e os benefícios decorrentes de sua implantação, assim como sugere sua aplicação na comunicação com clientes, como vantagem competitiva por unidades de informação, visto que otimiza os recursos disponíveis, através da disseminação de informações pertinentes, com redução de tempo e custos, além de proporcionar interação entre as partes.
\end{abstract}

Palavras-Chave

Redes Eletrônicas de Comunicação; Internet; Intranet; Intranet - Unidades de Informação.

\section{INTRODUÇÃO}

Com o advento do século XXI o mundo passa por profundas transformações de cunho social, político, econômico e, princi- palmente, tecnológico. Estágio de desenvolvimento denominado por muitos autores, de Sociedade da Informação, o qual Tofler (1980) já intitulara como Terceira Onda.

Tal estágio remonta à Segunda Guerra Mundial, quando foi construído o primei- 
ro computador digital, o Eniac, para automatizar o cálculo de tabelas balísticas, com crescimento exponencial no decorrer dos anos. Segundo Pontual (1994, p. 206), a informática é como a máquina a vapor foi, no século XVIII, a alavanca da Revolução Industrial, culminando com a Internet cujo uso, a partir da década de 90 , se propaga desenfreadamente, tendo sido aclamada como a mais revolucionária tecnologia, a qual extrapolou o contexto da computação e tomou forma junto à sociedade, provocando o surgimento da cultura do usuário de modem, e-mail, entre outros tantos recursos disponíveis na rede, associando a informação à velocidade e quebrando paradigmas de espaço e tempo.

De acordo com Gralla (1996, p. xi), a tecnologia da Internet pode ter seu maior impacto nos próximos anos, não na cultura em geral, mas sim nas corporações, sendo aplicada nas Intranets.

\section{EVOLUÇÃO DAS REDES ELETRÔNI- CAS DE COMUNICAÇÃO}

Segundo Ferreira (1994), redes de comunicação como hardware, software, fontes informacionais e recursos humanos promovem o compartilhamento e a otimização de recursos entre usuários de computador.

Existem vários tipos de redes que diferem de acordo com a capacidade operacional: LAN (Local Area Network); rede que compartilha softwares e impres- soras em um ambiente de trabalho; MAN (Metropolitan Area Network), interconecta LAN's em área metropolitana e WAN (Wide Area Network), interliga LAN's e MAN's em grandes distâncias geográficas.

A Arpanet, rede eletrônica de comunicação de dados, surge em 1970, na Advanced Research Projecto Agency (Arpa) do Departamento de Defesa dos Estados Unidos, com o objetivo inicial de compartiIhamento de recursos computacionais, bases de dados e recursos gráficos, entre as organizações de pesquisa do referido Departamento. A idéia era a construção de um sistema de comunicação que não pudesse ser interrompido por avarias locais, ou seja, que não possuísse uma central, e, dessa forma, não pudesse ser destruída, pois na época vivia-se o ápice da Guerra Fria. A Arpanet interligou quatro universidades americanas e algumas instituições militares, utilizando o protocolo NCP (Network Control Protocol) até 1982, quando foi substituído pelo TCP/IP (Transmission Control Protocol/Internet Protocol). Em 1983 a Arpanet é dividida, originando a rede militar Milnet, e a Arpanet passa a ser basicamente destinada à pesquisa científica.

Em 1978, teve início a Usenet que oferecia serviços como correio eletrônico e transferência de arquivos, e era baseada no programa Unix uucp.

A rede acadêmica Bitnet foi estabelecida em 1981 como uma rede cooperativa entre as universidades e cresceu muito nos 
anos que se seguiram. Os serviços básicos oferecidos pela rede são correio eletrônico, transferência de arquivos, mensagens interativas, acesso a banco de dados, sistemas de quadro de avisos e sistemas de listas de distribuição.

A Csnet, com o apoio da ARPA e da NSF (National Science Foundation), foi colocada em funcionamento em 1982, conectando os departamentos de Ciência da Computação das universidades americanas.

Na década de 80 surgem várias redes como Decnet, Hepnet, Janet, Vnet, Junet, entre outras.

O sucesso representado pela Arpanet e a baixa velocidade de suas linhas motivaram a comunidade acadêmica americana a estruturar sua própria rede. Assim, em 1987 a National Science Foundation (NSF) investiu em uma grande rede de alta velocidade, criando a Nsfnet. Surgiu com a implantação de seis grandes centros, com supercomputadores e em pontos estratégicos, facilitando a conexão de qualquer instituição. A Arpanet foi desativada em 1990 cedendo lugar à Nsfnet.

No início dos anos 90 a adoção do conjunto padrão de protocolos TCP/IP (Transmission Control Protocol/Internet Protocol) proporcionou a interligação de variadas redes, denominando-se Internet. zação comercial, pois a NSF retirou seu financiamento e, conseqüentemente, as imposições dele decorrentes.

A Internet com quatro anos de existência ultrapassou 50 milhões de usuários, combinando computadores e redes de comunicação.

Os serviços pioneiros da Internet são: correio eletrônico, conexão remota - Telnet e transferência de arquivos. A partir de 1994, a Worl Wide Web, desenvolvida nos laboratórios CERN, na Suiça, baseada em tecnologia multimídia, monopolizou a Internet, dada a sua interface gráfica e facilidade de utilização. Hoje, WWW é sinônimo de Internet.

Atualmente, existem inúmeras opções de uso da grande rede; é possível consultar bibliotecas, trabalhar em grupo, pesquisar em banco de dados, fazer compras, ler jornais diários, acessar revistas especializadas, bater papo, anunciar produtos, além de outras novidades que são acrescentadas periodicamente à teia.

Trindade Júnior (1997, p. 2) enfatiza que o crescimento da capacidade das redes de comunicação tem sido tão ou mais impressionante que o crescimento do desempenho dos computadores.

Em 1995 a Internet foi aberta para utili- 


\section{INTRANET}

A popularização da Internet propiciou às pessoas reconhecerem que o seu mecanismo também poderia ser eficiente dentro das organizações, com o uso de Intranet, que pode ser definida como o emprego de tecnologia Internet em rede privada corporativa ou educacional, baseada em arquitetura cliente-servidor, disponibilizando ferramentas, tais como correio eletrônico, consulta a base de informações, transferência de arquivos, videoconferência etc., sendo possível o acesso a setores da organização transformados em sites www. As informações nela contidas são acessíveis apenas às pessoas autorizadas a consultála. Segundo Zimmerman \& Evans (1997, p.19):

O propósito final da Intranet é encorajar e facilitar a comunicação entre funcionários de forma que eles possam empreender mais rapidamente seu trabalho essencial. O uso apropriado da Intranet pode simplificar muitos processos do trabalho e melhorar os bens e serviços produzidos.

A Intranet pode ser composta por várias redes diferentes dentro de uma organização que se comunicam através de protocolos TCP/IP (Transmission Control Protocol/Internet Protocol), os quais operam juntos na entrega de dados, ou seja, o Transmission Control Protocol quebra os dados em pacotes menores e recombinaos em seu destino, enquanto que o Internet
Protocol manipula o roteamento dos dados e os conduz para onde devem ser entregues. Dessa forma, o tráfego de uma Intranet é controlado por roteadores, que são uma combinação de hardware e software que direcionam a informação ao seu destino.

A World Wide Web incentivou o aparecimento de Intranets, porquanto incrementa a comunicação através do uso de HTML (Hypertext Markup Language) ou tecnologia Hipertexto, tendo em vista também as facilidades de incorporação de textos, gráficos, sons, animações e outros elementos multimídia.

Com o uso de software Groupware, a Intranet possibilita o trabalho integrado entre as pessoas da empresa de forma mais fácil e eficiente, pois permite que colaborem em projetos, compartilhem informações, façam videoconferência e participem de discussões.

Podem ser usados diversos programas para correio eletrônico, como o Microsoft Mail, Lotus Notes etc. A arquitetura que o fundamenta numa Intranet é o protocolo SMTP (Simple Mail Transfer Protocol).

A Intranet permite que a companhia fique conectada à Internet para que qualquer pessoa solicite seus produtos e serviços. A informação é enviada da Internet para a Intranet privada, possibilitando oportunidades de negócios. 
A implantação de uma Intranet exige plataformas de hardware comuns e o uso de protocolos TCP/IP em rede local, além de um sistema operacional como Unix e Windows NT. Para o cliente são necessários browsers como Netscape Navigator, Microsoft Internet Explorer e aplicativos de correio eletrônico e news. Destacam-se ainda os softwares servidores Web, FTP, Mail, News; recursos de pesquisa; ferramentas de autoria e de desenvolvimento.

Uma questão a ser considerada na implantação de Intranets é o sistema de segurança a ser adotado, visto serem vulneráveis a ataques de invasores. As medidas de segurança incluem combinações de hardware e software para controle de tráfego, criptografia e autenticação para prevenir o acesso não-autorizado à Intranet, software de rastreamento e bloqueio de vírus, software de bloqueio de sites de conteúdo impróprio e software de monitoração de tráfego.

A estrutura de uma Intranet depende do objetivo ao qual ela se propõe e dos clientes aos quais ela se destina. Dessa forma, os serviços oferecidos podem variar conforme as necessidades de comunicação na organização.

Graziadei (1996) ressalta a aplicação de Intranets basicamente em: publicação de documentos como cartas, listas de preços, anuários etc.; acesso a diretórios contendo agenda, políticas da organização, informações sobre recursos humanos, listas de te- lefones etc.; páginas Institucionais/ Departamentais/Individuais; distribuição de softwares; correio eletrônico com multimídia; aplicação de groupware.

Entre os benefícios decorrentes de aplicação de Intranets, destacam-se a redução de custos operacionais e prazos, interação entre as partes usuárias, otimização dos recursos disponíveis e maximização do uso da informação.

A economia que a aplicação de Intranet proporciona para as organizações refere-se à redução de: quadro de funcionários, custos com telecomunicações (telefone e fax), custos com correio e malotes, material impresso, número e duração de reuniões.

Gralla (1996) apresenta como benefícios de utilização a diminuição da quantidade de papel usado pelas corporações, a revolução na maneira pela qual as empresas vendem bens e serviços sem gastar muito, o acesso pelos usuários feito de suas casas ou da estrada, a disseminação de informações atualizadas e o uso como ferramenta de treinamento multimídia, incluindo fotos, vídeo e áudio ao texto.

Trindade Júnior (1997) acrescenta às vantagens mencionadas, confiabilidade, baixo custo de implementação, facilidade de utilização e garantia de desenvolvimento.

Bater (1997) enfatiza ainda a expan- 
são da informação corporativa, o aumento do lucro e a administração da informação transformando empresas.

Vale ressaltar a importância do Webmaster - o profissional que gerencia a Intranet e as informações nela contidas, e auxilia seus usuários - para o desenvolvimento de uma Intranet.

\section{O USO DE INTRANET EM UNIDADES DE INFORMAÇÃO COMO VANTAGEM COMPETITIVA}

Diante de tantas vantagens advindas da incorporação desta tecnologia tão recente, por que não adotarem as bibliotecas a Intranet na comunicação com seus clientes, sendo centros de informação e responsáveis pela disseminação da mesma? Partindo da premissa de que, se o usuário não vai até a biblioteca, a biblioteca deve ir até ele, seria uma maneira de os bibliotecários estarem aliando-se às tecnologias para o cumprimento do objetivo da unidade de informação e, dessa forma, otimizando os recursos disponíveis.

Unidades de informação podem utilizar esta tecnologia e disponibilizá-la aos seus clientes, através de home-pages, regulamentos, políticas em geral, bases de dados da biblioteca, títulos novos adquiridos, bases de dados em $C D-R O M$, sumários de periódicos correntes, serviços de DSI e de Alerta, estatísticas de utilização do acervo e serviços etc.
Os clientes podem interagir com a unidade de informação, solicitando levantamentos bibliográficos, títulos para aquisição, reserva de documentos, sugestões para melhorias nos serviços etc.

É possível também disponibilizar links para as home-pages da Internet que interessem aos clientes, como periódicos eletrônicos, bibliotecas, instituições de pesquisa ou qualquer outro site que seja pertinente.

Enfim, as possibilidades de uso são enormes, depende da criatividade, do espírito inovador dos profissionais que se dispuserem a usá-la na venda de produtos e serviços.

As informações disponíveis na Intranet podem ser acessadas por categorias de clientes. Segundo Bater (1997), a Intranet pode ser definida de acordo com o suporte a ser dado aos objetivos do negócio, ou seja, não todas as coisas para todas as pessoas, mas coisas diferentes para diferentes pessoas. Um exemplo seria, informações de cunho administrativo para clientes da área administrativa da Instituição, links de periódicos especializados na Internet para os respectivos especialistas, serviços de alerta, serviços de DSI para clientes determinados. Parodiando Ranganathan (1963), a informação certa para a pessoa certa. 


\section{CONSIDERAÇÕES FINAIS}

Segundo Wodehouse (1997), a combinação de CPU, armazenamento de informações, fibra ótica, redes, TCP/IP, servidores Web e browsers, mudou a direção da computação e tornou-a acessível a muitas pessoas.

Em linhas gerais, foram identificados como benefícios decorrentes do uso de Intranet, a otimização dos recursos disponíveis, através da disseminação de informações pertinentes, com redução de tempo e custos, e a interação entre as partes.

A adoção de Intranet por unidades de informação é um recurso de marketing, é uma vantagem competitiva, em que $o$ atendimento ao cliente está em primeiro lugar, o qual poderá acessá-la de qualquer máquina que disponibilize Internet, aumentando assim as possibilidades de interação com a biblioteca, além de implementar a qualidade do produto e agregar valor à informação. Segundo Taylor, citado por Kielgast \& Hubbard (1997), os processos que fornecem informação que ajuda o usuário a fazer escolhas, tomar decisões e esclarecer problemas, ou seja, tornar a informação útil, agrega valor a ela.

As unidades de informação devem fazer parte deste contexto tecnológico, fazendo uso das tecnologias emergentes, pois, se não pegarem carona no "desenvolvimento", correm o risco de se tornarem, no futuro, apenas unidades onde se armazenam documentos impressos.

\section{REFERÊNCIAS BIBLIOGRÁFICAS}

BATER, Bob. The inclusive intranet: linking into legacy systems. Aslib Proceedings, v. 49, n. 1, p. 21-24, 1997.

FERREIRA, Sueli Mara Soares Pinto. Introdução às redes eletrônicas de comunicação. Ciência da Informação, Brasília, v. 23, n. 2, p. 258-263, maio/ago. 1994.

GRALLA, P. Como funcionam as Intranets. São Paulo : Quark, 1996. 206 p.

GRAZIADEI, William D. The Intranet: revolution or evolution?. [online]. July 1996. [cited 1998-03-17]. Available from World Wide Web:

<http://137.142.42.95/slides/ intranetText.html >

KIELGAST, Soeren, HUBBARD, Bruce A. Valor agregado à informação: da teoria à prática. Ciência da Informação, Brasília, v. 26, n. 3, p. 271-276, set./dez. 1997.

MANDEL, Arnaldo, SIMON, Imre, LYRA, Jorge L. de. Informação: computação e comunicação. Revista USP. [online]. 1997, n.35. [cited 1998-06-18]. Available from Worl Wide Web: < http:/ /www.usp.br/geral/infousp> 
PONTUAL, M. de A. C. Inovação e transferência tecnológica na área de informática em institutos governamentais de P\&D. Ciência da Informação, Brasília, v. 23, n. 2, p. 206-216, maio/ ago. 1994

RANGANATHAN, Shiyali Ramamrita. The five laws of library science. Bombay : Asia Publishing House, [1963]. 449 p.

TOFFLER, Alvin. A terceira onda. Rio de Janeiro : Record, 1980. 491p.

TRINDADE JÚNIOR, Onofre. Intranets na USP: avaliação da tecnologia e recomendações. Revista USP. [online]. 1997, n.35. [cited 1998-07-22]. Available from World Wide Web: <http:/ /www.usp.br/geral/infousp/onofre.htm>

WODEHOUSE, Lord. The intranet: the quiet (r)evolution. Aslib Proceedings, v. 49, n. 1, p. 13-19, 1997.

ZIMMERMAN, S., EVANS, T. Construindo uma Intranet com o Windows NT 4. São Paulo : Makron Books, 1997. 568 p.

\section{Agradecimentos}

À Profa Dra Plácida Leopoldina V. Amorim da Costa Santos pela revisão do texto.

\section{Titulo}

La Evolución de las Redes Electrónicas de Comunicación y Uso Estratégico de Intranet por Unidades de Información 


\section{Resumen}

Presenta la evolución de redes electrónicas de comunicación, culminando con la propagación de Internet en la década de 90 y, después, el empleo de las Intranets en redes corporativas y educacionales. Define el tema Intranet, su funcionamiento y los beneficios provenientes de su implantación, así como sugiere su aplicación en la comunicación con clientes, como ventaja de competencia por unidades de información, ya que optimiza los recursos disponibles, a través de diseminaciónde informaciones pertinentes, con reducción de tiempo y costes, además de proporcionar interacción entre las partes.

\section{Palabras-Clave}

Redes Electrónicas de Comunicación; Internet; Intranet; Intranet - Unidades de Información.

Artigo recebido em: 30/06/99 